\title{
Why theory matters in correctional psychology
}

\author{
Theoretical illiteracy and therapeutic ineffectiveness
}

\section{Tony Ward ${ }^{1}$}

Received: 7 November 2019 / Accepted: 18 December 2019 / Published online: 10 February 2020

(c) The Author(s) 2020

\begin{abstract}
Contemporary forensic psychology is characterized by a relative lack of attention to theory building and conceptual analysis. In my view, this neglect of theory amounts to theoretical illiteracy and represents a significant obstacle to the explanation of crime and its management. In this paper I explore the problem of theoretical illiteracy for forensic psychological research and practice. First, I discuss why theory is important in science and the dangers of ignoring it. Second, I review the role of theory in addressing the myriad of practical problems facing human beings. Third, I outline three strategies to increase researchers and practitioners' appreciation of theory construction and development: adopting a more comprehensive model of scientific method, epistemic iteration, and promoting model pluralism. Fourth, I examine two examples of core concepts from correctional psychology, that of dynamic risk factors and classification, and demonstrate how the above strategies can be used to address problems with these constructs.
\end{abstract}

Keywords Classification $\cdot$ Theoretical illiteracy $\cdot$ Dynamic risk factors $\cdot$ Protective factors $\cdot$ Treatment

\section{Zur Bedeutung von Theorie in der Vollzugspsychologie}

Theorie-Illetrismus und therapeutische Ineffektivität

\section{Zusammenfassung}

Die forensische Psychologie ist derzeit durch ein relatives Defizit an Aufmerksamkeit für Theoriebildung und konzeptuelle Analyse gekennzeichnet. Aus Sicht des Autors läuft diese Vernachlässigung auf einen Theorie-Illetrismus hinaus und stellt ein erhebliches Hindernis für die Erklärung von Straftaten und deren Bewältigung dar. In der vorliegenden Arbeit wird das Problem des Theorie-Illetrismus für die forensisch-psychologische Forschung und Praxis untersucht. Zunächst wird diskutiert, warum Theorie in der Wissenschaft wichtig ist und welche Gefahren entstehen, wenn sie ignoriert wird. Zweitens wird die Rolle der Theorie beim Umgang mit den zahllosen praktischen Problemen, mit denen Menschen konfrontiert sind, untersucht. Dann werden 3 Möglichkeiten skizziert, wie Forschende und konkret Praktizierende die Theoriebildung und -entwicklung besser einschätzen können: die Annahme eines umfassenderen Modells wissenschaftlicher Methodik, die epistemische Iteration und die Förderung des Modellpluralismus. Viertens werden exemplarisch 2 Schlüsselkonzepte aus der Justizvollzugspsychologie überprüft: dynamische Risikofaktoren und Klassifikation. Dabei wird aufgezeigt, wie die beschriebenen Strategien eingesetzt werden können, um Probleme mit diesen Konstrukten anzugehen.

Schlüsselwörter Klassifikation · Theoriedefizite $\cdot$ Dynamische Risikofaktoren · Protektive Faktoren · Behandlung

This paper is based on a keynote address given at the Fachgruppe Rechtspsychologie Biannual Conference, Hildesheim, Germany.
Dr. Tony Ward

tony.ward@vuw.ac.nz

1 School of Psychology, Victoria University of Wellington, PO Box 600, 6012 Wellington, New Zealand 


\section{Introduction}

Contemporary correctional psychology is an applied discipline and unlike some applied professions such as medicine or engineering is characterized by a relative lack of attention to theory building and conceptual analysis (Ward et al. 2019). It draws its practice guidelines, methods and guiding ideas primarily (and narrowly) from conceptually thin risk management models such as Bonta and Andrews (2017) General Personality and Cognitive Social Learning Perspective (GPCSP) (Ward et al. 2007). While some areas of correctional psychology like sexual offending have developed a comprehensive range of explanatory theories (e.g., Beech and Ward 2017; Ward et al. 2019), practitioners largely rely on risk management models in their day to day clinical work. In other words, there is a reliance on content "light" theories to structure assessment and clinical work with individuals who have been convicted of crimes (Ward 2014). In this instance, the thinness of the theory is an indicator of its lack of explanatory power. The worry is that if theories underpinning practice are impoverished then the effectiveness of correctional and forensic interventions will be weaker as a result. Theories identify the causes of crime-related phenomena such as addiction or poor emotional control, and thereby provide assessment and therapeutic targets. An example of lack of attention to theory construction in forensic psychology is the failure to demonstrate that within treatment changes in dynamic risk factors (hypothesized causal factors; DRF) are responsible for reduced recidivism rates (e.g., Cording et al. 2016; Heffernan et al. 2019), ongoing questions about their theoretical coherence (e.g., Beech et al. 2016; Ward and Fortune 2016) and the relatively modest effect sizes for correctional interventions (e.g., Klepfisz et al. 2016; Schmucker and Losel 2015). A legacy of this lack of attention to a deeper theoretical analysis of dynamic risk factors is that we are not sure exactly how therapy is contributing to reduction in recidivism and even when treatment is effective, it does not appear to operate in the way we think (e.g., DRFs are not always reduced).

In this paper I explore the problem of theoretical illiteracy for correctional psychological research and practice. Theoretical and conceptual illiteracy is evident (a) when there is failure to understand the role of-and need for theory-in detecting and explaining relevant phenomena, (b) when there is a lack of competence and knowledge to critically evaluate ideas and methods, and (c) where prescribed practice has little or no relationship to strong scientific theories. First, I discuss why theory is important in science and the dangers of ignoring it. Second, I review the role of theory in addressing the myriad of practical problems facing human beings. Third, I outline three epistemic strategies to increase researchers' and practition- ers' appreciation of theory construction and development: adopting a more comprehensive model of scientific method, epistemic iteration, and promoting model pluralism. Fourth, I take two examples of core concepts from correctional psychology which are associated with significant conceptual problems, that of dynamic risk factors and classification, and demonstrate how these strategies can be used to rectify these problems.

\section{The role of theory construction and development in science}

There are a wide variety of cognitive tasks associated with theoretical work in science including conceptual analysis (e.g., what is meant by the concept of temperature? Chang 2004); explanation (e.g., what causes the symptoms of childbed fever? Carter 2003), prediction (e.g., why do some individuals sexually reoffend? Hanson 2009), and classification (e.g., should we classify on the basis of types of crimes, risk factors, or motives? Ward and Carter 2019). Each of the cognitive tasks associated with theoretical work is important in its own right and confers different kinds of benefits to both researchers and the wider public. For example, predictive models that identify individuals who are more likely to develop medical problems in the future can provide a sound basis for early intervention initiatives to lower the chances of disease developing. Alternatively, being able to classify offence-related problems in ways that reflect problematic social and psychological characteristics of individuals can assist policy makers to allocate scarce therapeutic resources in rational ways and also provide valid explanatory targets for theorists.

Explanatory theories are of particular value when it comes to developing intervention plans for individuals with psychological and/or offence related problems (Anjum and Mumford 2018). This type of theory seeks to account for the occurrence of phenomena (e.g., sexual arousal to children) by explaining why they exist and how they are instantiated. Theories enable us to go beyond what we can observe or experience by virtue of their ability to reveal patterns or underlying mechanisms at different levels of analysis, and their observable effects. While there are different kinds of explanatory theories (e.g., mechanistic, functional, statistical) they all aim to provide insight into the factors that cause events like disease or crime and maintain them over time.

The process of developing explanatory theories is a dynamic one, where there is an iterative relationship between analysis of patterns of data and the construction of theories of increasing specificity. Initially, models are no more than placeholders and are conceptually thin, essentially only consisting of a general label referring to a latent 
construct, for example, "infection," "empathy," "cognitive distortions", or "depression". Ideally, over time researchers converge on the processes constituting the phenomena and identify their proximal and distal causes. The model gets "filled out" and in an ideal world would ultimately consist of a detailed and rich representation of the structures and processes generating the relevant phenomena.

Unfortunately, in some research domains such as psychiatry or forensic/correctional psychology there has been little progress in formulating empirically supported models that make specific claims about disease/disorder aetiology, generate reliable predictions about probable clinical features, and prognosis, and identify potential treatments at the group level. Instead, existing models tend to simply describe collections of clinical phenomena that often occur together; they are essentially syndrome models. A worry with models like this is that they could be based on false assumptions about the nature of the target phenomena (i.e., the explanatory targets are not robust) or the underlying mechanisms (i.e., they do not exist). For example, some forensic researchers have recently argued that dynamic risk factors and protective factors do not exist; they are simply summary labels for a number of disparate causal factors, contextual features, and psychological attributes (Ward and Fortune 2016). Another example, is a failure in the sexual offending area to be clear about the nature of empathic responses (i.e., whether or not they involve emotional contagion, perspective taking, sympathy, or empathy-Maibom 2012) resulting in poorly directed theories of empathy deficits in individuals who commit sexual crimes (Barnett and Mann 2013).

\section{The application of scientific theories to practice}

There are literally thousands of examples from all areas of science illustrating the critical role of theoretical work in addressing practical social, physical, environmental, and psychological problems confronting human beings (Gaukroger 2016). I shall just give two examples to support my argument in this paper. A medical example of the relevance of theory development to practice is McArdle disease, discovered in 1951 by Brian McArdle based on his analysis of a single case study (Quinlivan et al. 2010). The patient reported muscle pain on exercise, which got worse as activity continued culminating in stiffness and weakness and ultimately, pain that only reduced with long periods of rest. McArdle theorized that the key pathology was an abnormality in the process of glycolysis within muscle tissue. McArdle's case description resulted in the formulation of an etiological model focused on myophosphorylase deficiency. The identification of a related set of clinical phe- nomena and the development of a subsequent explanatory model has resulted in more effective strategies to manage symptoms of the disease.

An example of the practical importance of theoretical work from the sexual offending area was the hypothesis that there are multiple paths to relapse not merely the one postulated by the prevailing relapse prevention model (RP) at the time. Following a theoretical analysis of the key assumptions of the RP model, Ward and Hudson (1998) argued that it contained several conceptual confusions and, more worryingly, proposed that most cases of sexual reoffending occurred through a process of disinhibition; individuals simply lost control. However, empirical research and theoretical model building suggested that some people saw sexual offending in a positive light and believed that it was likely to promote important personal goals like the attainment of intimacy; in fact, they demonstrated excellent behavioral control. The resulting Self-Regulation Model of the relapse process (Ward and Hudson 1998) contained four primary sexual reoffending pathways, ranging from loss of control to explicit and often sophisticated planning. This model lead to significant theoretical growth in our understanding of sexual offending and better tailored treatment programs.

\section{The dangers of ignoring theory}

A lack of theoretical literacy can take a number of specific forms: (a) uncritical and dogmatic acceptance of existing theories; (b) view of science as strictly empirical in nature; (c) failure to clarify — or see the utility of clarifying - the meaning of key constructs; (d) seeking the "one true theory" and rejecting the possibility of theory pluralism, (e) embracing impoverished theories of method; and (f) failure to distinguish distinct epistemic tasks. For the purposes of this paper I assume that each of these problems is a genuine example of theoretical illiteracy and now comment on them in greater detail.

\section{Uncritical and dogmatic acceptance of existing theories}

It makes sense for researchers to commit themselves to theories that have the best track record in their research domain. Thomas Kuhn (1970) talked explicitly about "normal science" when scientists share a commitment to a paradigm that spells out what constitute acceptable research questions, designs, analytic methods, and problemsolving strategies. Approaches that challenge the prevailing paradigm are often marginalized, and results that contradict favored theories are either explained away or ignored. From a knowledge generation perspective this might make sense: why not allocate precious financial and cognitive resources to problems and theories that have stood the test of time? 
The trouble is that if disparate perspectives and criticisms are effectively shut down, then there are few alternative theories available to take over when things inevitably things go wrong. An example of theory dogmatism in the sexual offending area is the view that sexual crimes (including rape) are primarily motivated by deviant sexual interests and desires. The mistake was to infer that because offending behavior was sexual in nature the primary underlying causes must necessarily be so as well. However, behaviors can be multiply determined, and be associated with differing intentions and goals. It is now accepted that there are multiple etiological pathways to sexual offending, only some of which involve deviant sexual preferences (Beech and Ward 2017).

\section{View of science as strictly empirical in nature}

Theories are deemed suspect if they contain constructs that go beyond experience, for example, psychopathy, intimacy deficits, personhood, the self, or human needs. Each of these constructs contains "surplus" meaning that cannot be operationalized in terms of actual or potential experience. What actual or potential set of experiences could explicate the meaning of human need? The concept of need is in part based on metaphysical and normative views of heathy human functioning and nature, and is not able to be translated into specific experiences. Exploring the layers of meaning associated with scientific concepts requires theoretical analysis (Schindler 2018).

The overriding commitment of most western correctional agencies to current risk management approaches to correctional research and their apparent intolerance towards theory construction is an example of this type of problem (Andrews and Bonta 2010; Bonta and Andrews 2017; Heffernan and Ward 2019). This approach relies on statistical analyses of large data sets from which possible causal variables and principles of effective rehabilitation are inductively inferred. Theories within this tradition are usually evaluated according to their fit with data rather than epistemic criteria such as their heuristic value, explanatory depth or coherence (Schindler 2018).

\section{Undervaluing the importance of conceptual analysis}

In part because of the emphasis on data collection in some research domains and distrust of what are considered to be "philosophical" methods, often key terms are not systemically analyzed. An instructive example in the correctional area is the lack of analysis of the concepts of DRF and protective factors despite their pivotal role in ongoing research, assessment and practice (Heffernan and Ward 2017; Ward 2016). The three major principles of the Risk-Need-Responsivity Model of correctional rehabili- tation (RNR; Bonta and Andrews 2017) are conceptually dependent on the construct of DRF. Its coherency and straightforward relationship to the causes of crime is simply assumed. Unfortunately, recent analyses have revealed significant conceptual problems with this core idea, throwing considerable doubt on its ability to support such a heavy theoretical load (Thornton 2016; Ward and Fortune 2016).

\section{Seeking the "one true theory" and rejecting epistemic pluralism}

Epistemic pluralism is the view that in science it is a good idea to actively pursue several parallel and competing theories of the same phenomena, at the same or at different levels of analysis. In contrast, the mono theoretical position is that there is in principle only one "true" theory ultimately capable of accounting for a specific set of phenomena under consideration. While it may take quite some time to arrive at truth, stringent theory testing and increasingly refined measurement will ultimately lead to the best theory; the one true account. A problem with this approach to theory generation is that it quickly leads to dogmatism and intolerance of other, competing theoretical perspectives. It could also result in the premature rejection of theories that may still offer much despite possessing significant flaws. In the correctional domain, the decision to reject functional or psychological classification schemes based on needs or motives in favor of offense and risk based classification has resulted in impoverished treatment planning (Ward and Carter 2019). A pluralist approach would have been to either (a) pit one against the other across the different arenas of prediction and treatment planning and to see how it played out or (b) develop different classification schemes for different arenas of correctional practice: a need/motive oriented system for treatment and a risk level framework for predictive purposes.

\section{Embracing impoverished theories of method}

A theory of scientific method provides researchers with a plan of inquiry that can guide the search for scientific phenomena (e.g., symptoms, chemical reactions) and the construction of explanatory theories to account for these phenomena (Haig 2014). The two dominant theories of scientific method evident in psychology privilege the collection of data and neglect theory. This can rapidly lead to conceptually impoverished scientific programs. These two theories of method are inductivism which recommends constructing theories on the basis of empirical generalizations, and hypothetico deductivism with its focus on the construction of theories through conjectures and testing via deductive reasoning processes. These methods provide minimal guidance on how to create theories, and evaluation is pri- 
marily concerned with empirical testing. What is arguably needed to develop good theories is a model of scientific method that divides the inquiry process into distinct phases, some of which are directly focused on inferring underlying causal mechanisms generating phenomena, and the development and evaluation of integrated theories. An example of the problems of relying on the inductive theory of method in correctional psychology is research guided by the General Personality and Cognitive Social Learning Perspective (Bonta and Andrews 2017), the theoretical source of the risk principles of risk, need, and responsivity (the RNR model; Andrews and Bonta 2010; Ward and Fortune 2016). In this research, statistical techniques such as factors analysis are employed to identify risk factors, which are then construed as possible causes of crime without engaging in in-depth conceptual analysis or theoretical modeling.

\section{Failure to distinguish distinct research tasks}

There are a variety of cognitive tasks undertaken by scientists including the formulation of research problems, phenomena detection, phenomena description, classification, prediction, and etiological explanation. Each of these tasks can be further broken down into subtasks, for example, the development of etiological theories involves the clarification of key concepts, constructing a model, its elaboration, and evaluation against a number of theory appraisal criteria (e.g., internal consistency, external coherence, fertility, explanatory depth, empirical adequacy-Schindler 2018). It is important for researchers to keep in mind exactly what tasks they are currently engaged in, otherwise mistakes can be made. A good example of this problem in cognitive neuroscience is to assume that the descriptive task of mapping associations between neural activity patterns and psychological functions such as emotion detection provides an explanation of the latter. Knowing that individuals with psychopathic traits show reduced neural responses on functional Magnetic Resonance Imaging scans in several key regions (e.g., amygdala and also ventral prefrontal regions) does not show that that psychopathic traits are caused by abnormalities within the brain (Ward et al. 2018). These studies only provide a description of the different types of neural patterns that constitute what is termed "psychopathic" functioning and have no etiological import. Another example from the area of risk prediction is illustrative. While dynamic risk factors may predict reoffending, this does not mean that they cause it and, more specifically, that they are valid treatment "targets" (Beggs 2010; Cording et al. 2016). To assume they are is arguably to conflate the tasks of prediction and explanation, without demonstrating theoretically that this is justified.

\section{Strategies to counter "theoretical illiteracy"}

There are numerous ways to cultivate theoretical literacy in pure and applied scientific domains at an institutional and individual level. In this paper, I examine three epistemic strategies for improving theoretical literacy in greater depth: adopting a comprehensive model of scientific method; utilizing the concept of epistemic iteration; and embracing model pluralism. I argue that as a set these three strategies are likely to reduce the chances of theoretical illiteracy and the subsequent adverse effects on research and practice that follow from this problem.

\section{Theory of scientific method}

In essence, scientific method is a general plan of inquiry detailing how scientists should go about identifying and describing phenomena, and how to construct valid explanatory theories. A variety of theories of scientific method have been proposed in the literature ranging from the Hypothetico-Deductive method (Nola and Sankey 2007) with its stress on theory testing to more recent comprehensive models such as the Abductive Theory of Method (ATOM; Haig 2014). In brief, according to ATOM there are a number of conceptually distinct phases in scientific inquiry: establishing the focus of inquiry; detecting and describing phenomena, inferring the underlying causal mechanisms generating each phenomenon, and finally the development and evaluation of integrated theories. Each of these different phases is associated with its own unique set of research problems.

In my view, ATOM has the breadth required in a theory of scientific method to guide every aspect of scientific inquiry. ${ }^{1}$ While it pays equal attention to empirical investigation and theoretical work, conceptual tasks are evident throughout all of the different phases of inquiry. In addition to model development, formulating problems of different kinds is partly a conceptual task as is the construction of measures and technologies to gather and analyze data. Thus the first epistemic strategy to counter the problems of theoretical illiteracy outlined above is to utilize a comprehensive and flexible theory of scientific method; ATOM provides such a method. First, by virtue of the fact that it takes theory development and conceptual analysis seriously, it minimizes the chances of uncritically accepting ideas, methods, or theories and refusing to consider other options. Second, as stated above, ATOM gives theory construction and conceptual analysis a major role to play in the practice of science and this avoids the problems associated with an overly narrow empiricist approach. Third, while it

\footnotetext{
${ }^{1}$ ATOM is simply used as one example of a comprehensive theory of method and nothing in my overall argument depends on adopting it as the definitive view of scientific method.
} 
does not explicitly endorse pluralism, its fallibilistic view of knowledge means that it is not committed to the search for the single, "true" unified explanations of phenomena within a domain of interest. Fourth, ATOM is a comprehensive theory of scientific method and is able to provide guidance to researchers throughout the different phases of inquiry. Finally, its rich conception of scientific problems and the varying epistemic tasks associated with detecting phenomena and developing models means that it encourages researchers to be explicit about the tasks they are engaged in at any particular time.

\section{Epistemic iteration}

Epistemic iteration is a strategy for acquiring knowledge when the starting point is one of relative ignorance by gradually revising and updating key assumptions around phenomena of interest (through an iterative process known as 'bootstrapping'). Its major contribution is in the inquiry phases of phenomena detection, phenomena description (through descriptive or compositional modeling), and the creation of classification schemes. Chang (2004, p. 45) defines epistemic iteration as a knowledge generating process where "successive stages of knowledge, each building on the preceding one, are created in order to enhance the achievement of certain epistemic goals." The goals could be to create a systematic classification system of species, to construct a predictive model for sexual reoffending, or to explain why certain psychopathology symptoms occur. Over time, progress occurs through the gradual "enrichment" of the theory being developed or some type of "selfcorrection" where erroneous earlier ideas are replaced by more valid ones (Chang 2004, p. 228). For example, temperature was first measured by reference to bodily sensations of hot and cold and then gradually progressed to the construction of thermometers (Chang 2004). The earlier belief that bodily sensations tracked objective temperature shifts was revised and replaced by the conceptualization of units of temperature, as measured by the rise and fall of mercury in a marked tube. As the iterative process unfolds a number of outcomes are possible (see Chang 2017) ranging from: differentiation between heterogeneous ideas that were previously treated as homogeneous (e.g., refinement of the concept of the relapse process into multiple, distinct pathways); rejection of ideas as untenable (e.g., abandoning the view that homosexuality is a mental disorder); or convergence where further change and development fails to yield additional knowledge gains (e.g., acceptance that risk assessment requires the employment of actuarial measures). There is a commitment to fallibilism and it is accepted that we are unlikely to ever arrive at a complete, perfect understanding of the world. Our knowledge is at best only tentative and liable to be incorrect in some respects (i.e., we are fallible knowers).

Epistemic iteration encourages theoretical analysis and model construction in order to make space for the injection of new ideas and knowledge development. By doing so, a number of the impediments to theoretical literacy are addressed. First, because of a commitment to fallibilism, there is little danger that researchers will uncritically adhere to existing theories and conceptual frameworks in their current form. This should help to combat dogmatic adherence to ideas. Second, ideas are viewed as critical to successful scientific practice alongside empirical research. Third, conceptual analysis is accepted as an integral aspect of knowledge acquisition. Fourth, epistemic iteration sits comfortably with model and method pluralism and directly encourages the subdivision of ideas into new models if it seems promising. Finally, distinguishing the distinct epistemic tasks to be addressed in a project is necessary for the iterative process to begin. For one thing, it is necessary to know whether the focus of inquiry is classification, methodology, prediction, or explanatory model building in order to work out what to do, and evaluate how well you have done it.

\section{Model pluralism}

In explanatory pluralism, different kinds of explanation provide alternative views of specific phenomena, for example, a reductive explanation of Attention Deficit Hyperactivity Disorder (ADHD) in neurobiological terms versus a macro level explanation where classroom and social practices are invoked to explain children's distractible behavior (Vreese et al. 2010). Each explanation provides a potentially valuable and unique account of ADHD and suggests distinct treatments and policies. Model or epistemic pluralism is a slightly different view where the development of theories at the same or different levels of analysis is actively encouraged. An example of model pluralism at multiple levels is when anhedonia (a core symptom of depression) is modeled at different levels of analysis (e.g., biochemical, neural networks, psychological processes, phenomenological) with the result that you end up with "coalition of 'friendly' models each focusing on a specific set of processes and structures at varying spatial scales and levels of abstraction" (Ward and Clack 2019, p. 46). An advantage of cultivating theory pluralism of any type is that it creates greater tolerance of competing perspectives, which in turn maximizes the chances of discovering new phenomena and developing valid explanations (Chang 2012). Furthermore, there is the possibility that there will be some degree of integration and cross fertilization between theories, which could result in richer explanations (Chang 2012). An example of cross fertilization is the integration of cognitive 
psychology with neuroscience to provide a new suite of explanatory theories and a new subdiscipline in psychology, cognitive neuroscience (Craver 2007; Hochstein 2016).

One thing all forms of pluralism have in common is the value they place on promoting diverse ideas and methods in scientific practice. Whether the goal is competition, integration, or multilevel description there is a realization that theoretical work is necessary for a vibrant and flourishing scientific culture. Ideas matter. Theoretical pluralism helps to enhance theoretical literacy (and counter theoretical illiteracy) in a variety of ways. First, because pluralism is committed to theoretical diversity and the coexistence of ideas, it is unlikely to lead to uncritical and dogmatic acceptance of existing theories. Second, by definition it is associated with an investment in theoretical work, and this includes model construction, development and conceptual analysis. Third, it explicitly rejects the very idea of a "one true theory" within a domain, regarding this norm as likely to result in knowledge stagnation. Fourth, pluralism extends to methods as well as explanatory theories and as such is committed to an enriched model of scientific method. Finally, pluralism in its epistemic form respects the multiplicity of scientific tasks including prediction, classification and explanation.

\section{Examples of theoretical problems in correctional psychology: Dynamic risk factors and classification}

\section{Dynamic risk factors}

In the correctional domain, DRF are conceptualized as changeable factors such as intimacy deficits or emotional dysregulation that are associated with an increased chance that individuals will reoffend. They are derived from the statistical analysis of large data sets demonstrating that certain variables are statistically associated with higher and lower rates of reoffending (Bonta and Andrews 2017). In essence, they are inductively inferred and their theoretical conceptualization is typically fairly sparse. Part of the reason for this can be traced to their origins in measures of psychological properties hypothesized to be important in causing crime and recidivism. As psychometric constructs, each DRF is really only an aggregate score representing the statistical association between different variables, which is thought to reflect a common factor or underlying latent construct (Slaney 2017). For example, Mann et al. (2010) identified a number of empirically supported "psychologically meaningful" (DRF) risk factors for child sexual abuse which included sexual preferences for children, emotional congruence with children, offence supportive attitudes and lack of adult intimate relationships (Mann et al. 2010).
While they gave brief narrative descriptions of these DRF, there was no attempt to present coherent theoretical definitions or to depict the mechanisms that cause and constitute them. In addition to their status as risk predictors, DRF are usually regarded in the correctional research and practice domain as potential causal factors that, if effectively targeted by cognitive behavioral techniques, will reduce reoffending rates. Thus they have a dual status: potential causes of crime and dynamic predictors of reoffending.

With respect to their theoretical status, researchers have identified a number of significant conceptual weaknesses in the current formulation of DRF. In the following discussion, I will consider the possible role of the three epistemic strategies outlined earlier in avoiding the problems with theoretical literacy associated with DRF research and practice. Formulating these criticisms in terms of the six types of theoretical illiteracy outlined earlier:

\section{Uncritical and dogmatic acceptance of existing theories}

DRF are viewed as possible causes of reoffending despite little evidence that they play a causal role in initial offending or recidivism rates (Ward and Fortune 2016). In addition, treatment outcome studies investigating the degree to which changes in DRF during treatment predict reduced reoffending rates have yielded disappointing - and inconsistent-results (Cording et al. 2016; Heffernan et al. 2019). The continued insistence that DRF are potential causes despite this lack of evidence reveals a degree of dogmatism and a strong commitment to risk management models of crime. It is clear that if researchers undertake research guided by a stronger theory of scientific method such as ATOM, the problems of theoretical literacy noted above are more likely to be avoided. DRF will be viewed as indicators of problems associated with crime and this will encourage researchers to consider alternative ways of conceptualizing them, possibly utilizing strength-based as well as risk-oriented models. The use of iteration (bootstrapping) techniques should introduce a degree of epistemic humility and remind researchers that their DRF-based predictive, explanatory, and treatment models are provisional at best. Finally, theory pluralism should reduce temptations to rigidly adhere to any particular methods and models of DRF and create conceptual space for the interaction between alternative ideas.

\section{View of science as strictly empirical in nature}

DRF are really just theoretical placeholders for future modeling and they have impoverished conceptual content. In addition, they represent different types of possible harm and thus are heavily value laden (e.g., the DRF intimacy deficits is only considered a risk factor because it is associated with 
harm to victims, a disvalued condition). The use of ATOM will remind researchers that science has a strong conceptual dimension as well as an empirical one, and encourage them to think explicitly about the mechanisms causing and constituting DRF. Exploring DRF and non-crime related problems in a dynamic way (epistemic iteration) over time may reveal commonalties between them and result in a focus on the individuals' core problems such as threat appraisal dysfunction, rather than artificially dividing them into anxiety symptoms and aggressive behavior. Theory pluralism extends to values and should prompt researchers (and clinicians) to think explicitly about what type of value conflicts are associated reoffending and how they impact on individuals' behavior.

\section{Undervaluing the importance of conceptual analysis}

DRF suffer from the conceptual problems of poor specificity (there are multiple possible causal factors associated with each one) and incoherence (each DRF is effectively just a label for a wide variety of constructs including possible causes, contextual variables, and mental state factors). It is not clear whether they are best viewed as summary labels for predictor variables (i.e., they do not really exist as particular kinds of entities) or are latent constructs that causally generate their associated predictor indicators. Conceptual analysis is a core component of scientific inquiry at all its phases, but especially when deciding on the focus of inquiry problem and detecting phenomena. The use of ATOM will remind researchers to ask direct questions about the meaning of core concepts in a program of research. In addition, noting that DRF lack specificity and coherence is an excellent place to employ epistemic iteration to tease out the various conceptual strands embedded within the DRF categories and to formulate them with greater precision. For example, the general DRF of intimacy problems can be subdivided into emotional identification with children, lack of communication skills, lack of concern for others, social rejection, and so on. Emotional identification with children may be further divided into fear of adults, feeling like a child, viewing children as sources of emotional reward, seeing children as more accepting, being able to understand children, and so on (Thornton 2013; Ward and Fortune 2016). Refining DRF in this way may result in substantial theoretical progress and a richer description of the specific kinds of problems individuals who sexually offend against children exhibit in various domains. Approaching the analysis of DRF categories from a pluralist perspective means that there is a deliberate attempt to develop a range of contrasting perspectives and to explore to what extent they can interact in ways that improve understanding and practice.

\section{Seeking for the "one true theory" and rejecting epistemic} pluralism

In the correctional domain DRF are usually embedded within the RNR model of rehabilitation and have their theoretical grounding in Bonta and Andrews (2017) General Personality and Cognitive Social Learning perspective. There appears to be little willingness to acknowledge they can be reformulated in terms of agency constraints or protective factors (see Ward and Fortune 2016). Furthermore, the possibility of cultivating theory pluralism seems to be off the table, gauging from the lack of creative theoretical work on DRF (although see Thornton 2016). Approaching DRF with a comprehensive theory like ATOM, means that research will be broken down into distinct phases. First, there will be an attempt to detect the phenomena or "symptom" like features associated with DRF and their various components that constitute them will be modeled at different levels. For example, the DRF of self-regulation deficits has causal (e.g., lack of self-management skills), contextual (e.g., chaotic lifestyle), and mental state (e.g., feeling overwhelmed by emotions) features. Second, researchers will be encouraged to investigate the mechanisms that generate the symptomatic aspects of DRF and consider a range of possible explanations (e.g., differentiating between the cognitive and affective components of intimacy deficits). All of these distinct research problems and their respective cognitive tasks can reasonably be expected to result in a nuanced approach to theory building. In addition, the endorsement of theory pluralism should offset any tendency to prematurely reject alternative models in favor of a single unified explanation of DRF. From the viewpoint of theory pluralism there is no such thing as the "one true theory" of DRF. The use of epistemic iteration with its commitment to fallibilism should also help to combat a monistic orientation to explaining DRF.

\section{Embracing impoverished theories of method}

Some of the theoretical problems noted above appear to have their basis in the nesting of risk management research within inductivist or hypothetico-deductivist models of scientific method. Both of these theories of method privilege empirical research and place relatively little value on intensive theory construction and development (including conceptual, analysis-Ward 2014). However, because ATOM incorporates multiple types of inference (i.e., induction, deduction, abduction and causal reasoning) and makes room for related but distinct sets of scientific problems, both descriptive and explanatory work are considered legitimate scientific tasks. Thus, researchers will be expected to develop coherent conceptualizations of DRF and to situate these within detailed models of the mechanisms causing and 
constituting them. In addition, there will be a stress on careful analysis of DRF indicators in order to detect phenomena and test models of DRF. Theory pluralism will ensure researchers develop a range of models of DRF, while epistemic iteration coheres well with ATOM's evolving multiphase model of inquiry.

\section{Failure to distinguish distinct research tasks}

The conflation of risk prediction and explanation evident in the literature on DRF is in part due to the adoption of theories of method that understate the importance of theoretical work. If researchers have a rich characterization of scientific problems and model of the inquiry process, then they will automatically explicate what specific cognitive task they are engaged in at any point in time. Without this guidance, it is easy to oversimplify matters and believe that attention to the factual basis of science will be sufficient to develop good scientific explanations and effective practice. According to ATOM, each of the phases of the inquiry process is characterized by a distinct suite of problems, which can be roughly divided into descriptive and explanatory phases. Addressing the problems at each of these general phases requires researcher to clearly state the question they are trying to answer. For example, preliminary questions could be: What do I mean by the concept of DRF? What are their key attributes? How should I break them down? Do they exist at different levels? And so on. In the explanatory phase, questions will revolve around the modeling process and their development and evaluation: What are the causes of DRF? What are they composed of? Would multilevel models provide a useful description of this DRF? Should I model them in functional (e.g., information processing stages) or mechanistic terms? Or both? What evaluation criteria should I prioritize: empirical adequacy, explanatory depth, coherence or heuristic value? And so on. Research problems phrased as questions will help researchers to be clear about exactly what tasks they are engaged in and to lessen the chances of them incorrectly shifting from the context of prediction to that of explanation. Epistemic iteration, with its stress on developing refined and theoretically rich categories from initially thin ones, also begins with some rather basic initial questions: What am I trying to do: explain, classify or predict? Where is my starting point? Finally, theory pluralism is much more relaxed about possible category mistakes with respect to models. It encourages the development of a variety of perspectives about a specific phenomenon or issue. This could mean that researchers intentionally attempt to create models that predict and explain, and also sharply separate them in another explanatory strategy. The aim is to build a wide range of explanatory models that lead to different empirical projects, and then to see which ones prove to be the most successful in solving the problems under consideration, in this case, crime.

\section{Forensic classification}

Scientific classification is usefully construed as the sorting of phenomena into non-arbitrary groups or sets of categories based on their core features or properties, for example, the types of symptoms associated with different kinds of diseases (Wilkins and Ebach 2014). This may occur prior to the development of explanatory theories although it is a conceptual task as it involves judgments about how certain phenomena should be grouped together. Wilkins and Ebach (2014, p. 18) characterize classification in the following way: "To classify is to order the data, to find regularities even if you have no distinct idea why they cluster so. It is to find identity classes empirically, setting up some problem or thing in need of explanation." The identification of scientific categories is important as they license researchers to make inferences about the entities in question (e.g., the course of a disease or behavior of a particular animal) and to predict outcomes based on an understanding of their central properties. Phenomena can be classified in different ways, depending on the goals and theoretical allegiances of researchers (Borsboom 2017; Wilkins and Ebach 2014). For example, in the area of psychopathology classification could be based on structural aspects of disorders (i.e., signs and symptoms) or in terms of their function (e.g., inability to meet specific types of need).

The classification of individuals on probation, in forensic settings or in prison is traditionally based on the types of harm they have caused to other people and the related actions that have led to these harms. Sorting individuals, the crimes they commit, and their crime-related problems into types is an important first step in the science and practice of forensic and correctional psychology. It helps researchers to concentrate on key problems and provides a common language for communicating their results to each other. $\mathrm{Ab}-$ stracting away irrelevant individual differences and concentrating on core properties shared by those convicted of different kinds of crimes makes it easier to describe their problems and ultimately to develop better explanatory theories. In the practice arena, treatment programs are typically developed according to types and subtypes of offences, for example, violent or sexual offending (or those who commit rape versus child molestation). In addition, clustering crime related problems into types based on factors such as kinds of crime, risk level, or dynamic risk factors enables practitioners to identify therapeutically useful treatment targets, and assign individuals to appropriate treatment programs and interventions (Bonta and Andrews 2017). Often the categories are used together, and different types of crime are subdivided according to risk level, with specific dy- 
namic risk factors identifying the types of changeable risk factors present. I will now briefly formulate criticisms of the practice of classifying individuals in terms of offense type, risk level, and DRF with respect to the six types of theoretical illiteracy outlined earlier. Alongside criticism, I will explore how utilizing the three strategies of pluralism, adopting a comprehensive theory of scientific method, and epistemic iteration can address them.

\section{Uncritical and dogmatic acceptance of existing theories}

Classification practices in forensic psychology have proceeded in the absence of explicit discussion of the role of classification in science (Ward and Carter 2019). In part this is due to the applied nature of forensic and correctional psychology and its stress on reducing reoffending rates. The theoretical legitimacy of basing the classification of offending related phenomena on properties such as type of crime, risk level or dynamic risk factors is simply assumed, not argued for (Ward and Carter 2019). To many it seems intuitively obvious that people who commit crimes such as fraud or violence do so because of their underlying antisocial dispositions; features that cluster together. It is assumed that classifying individuals according to the offences they commit, their level of risk, or number and type of dynamic risk factors captures all that is needed to effectively explain and reduce their chances of committing further crimes.

According a pluralist perspective, I think this is a mistake and that it is important to critically examine the use of classification systems based on crime in forensic and correctional practice and to consider alternative ways of classifying crime-related problems. For example, rather than focusing solely on the characteristics of individuals who harm others, concentrating on motivational systems, their associated goals, and the affordances (opportunities) provided by the environment provides greater understanding of the meaning of the individuals actions and how they are connected with non-offending aspects of their lives. That is, we ought to ask: What social and/or psychological tasks is the person engaged in? What outcome(s) are they implicitly or explicitly attempting to bring about (e.g., threat management, status enhancement, affiliation, care giving, mate seeking or resource acquisition-Ward and Carter 2019)? Adopting a comprehensive theory of method such as ATOM with its division of inquiry into descriptive and explanatory phases makes it easier to think about the different roles classification systems play in science, and also to explicitly consider a range of possible systems. Relatedly, in conjunction with pluralism, there is acceptance that different types of classification offer different things, such as those developed for prediction purposes (e.g., based on risk level) versus those intended to guided intervention (e.g., based on function or goals). Finally, the process of epistemic iteration can help researchers to grasp that the development of good classification systems can takes time and necessarily starts with fairly rudimentary categories. Both conceptual analyses and empirical research should be utilized to gradually develop a system, whether that ultimately entails its subdivision into different classification systems (e.g., offense types being replaced by risk bands) or the combination of different categories into an integrated classification system (e.g., risk levels supplemented by protective factors and DRF). For all of these tasks, it is necessary to engage in critical analyses.

\section{View of science as strictly empirical in nature}

Classifying people based on their kind of offence fails to subdivide them into meaningful psychological and behavioral categories. A significant issue-contrary to the assumptions of risk-oriented researchers and practitioners-is that what constitutes an offence (or type of offence) is normatively defined. The assumption made is that when criminal laws are broken, individuals and members of the community are significantly harmed, and that the types of crime (e.g., sexual offences and violent offences) specify the types of harm and their sources. The problem with incorporating normative concepts into correctional categories is that the categories themselves are derived with reference to social, political and legal institutions, meaning that treatment intervention based on these categories will not necessarily be targeting the causal features of the problematic behavior.

Implementing the strategy of model of explanatory pluralism when constructing different types of forensic classification systems makes it more likely that both the normative and factual aspects of classification will be taken into account. For example, classifying for treatment will be based on well-being related or prudential values as well as the level of psychological skill and knowledge possessed by individuals. Whereas, if the aim of a classification system is to predict the risk of reoffending then the guiding values will be ethical in nature (e.g., likelihood of harming others) and the factual basis related more to moral psychological features such as impulsivity or antisocial attitudes. With respect to the value of adopting a comprehensive theory of method, it is clear that problem formulation in science and theory evaluation rely on different types of values as well as knowledge-related considerations such as the depth of an explanation. A method such as ATOM has the theoretical resources to incorporate this diversity and to specify what kinds of values and factual issues are salient at different times of the classification construction process. Finally, epistemic iteration is based on normative and factual criteria as it is in part driven by researcher interests and in part by an awareness of the factual constraints in operation. For example, if the aim is to classify individuals for 
treatment, then an appreciation of the role of human needs in adaptive functioning is necessary and this concept is in part normative (i.e., what is essential for healthy functioning) and partly factual (i.e., determining what psychological and physical mechanism underlie need satisfaction).

\section{Undervaluing the importance of conceptual analysis}

Categories based on types of offenses are relatively thin; the only property in common is the type of crime committed, for example, a sexual or violent offense. This problem arises from the heterogeneous nature of offenders, who often present with distinct and sometimes contrasting clinical profiles (Marshall et al. 2006). For example, one person may be socially unskilled, fearful of other people, and struggle to manage negative emotions while another could be socially high functioning and only possess a single problem such as deviant sexual interests (Mann et al. 2010). Assuming that persons who commit a particular type of crime all manifest similar behaviors and difficulties reflects an overly simplistic view of the complex nature of human behavior, and fails to allocate offenders to intervention programs tailored to their individual needs (Taxman and Caudy 2015). Hence, classifying offenders based on their offence type does not provide meaningful categories as it does not highlight therapeutically useful treatment targets. We propose that offender classifications should focus on the cluster of problems exhibited by an offender, rather than on the offending behavior itself.

Furthermore, as stated earlier, the concept of DRF is a hybrid or composite one and thus theoretically incoherent. What we mean by theoretical incoherence is that DRFs are comprised of different kinds of conceptual categories and lack the integration required for use as explanatory constructs in research or practice contexts. However, somewhat ironically, the internal complexity of DRFs means that they are likely to be valuable predictors of re-offending (Ward 2016). Nevertheless, in their current conceptualization the role of DRFs in correctional classification is unwarranted and largely display poor practical utility.

Theoretical pluralism involves the construction of classification systems (a lower level theoretical task) of different types, at different levels of analysis. For example, self-regulation pathway models of reoffending (Ward and Hudson 1998) or typologies of violent offenders based on physiological indices such as heart rate variability (Raine et al. 2006). The development of each of these classification systems in part depends on the analyses of the key concepts involved, such as heart rate variability or offense pathways. Utilizing a comprehensive theory of scientific method such as ATOM is likely to remind researchers of the importance of addressing theoretical issues in the process of classification development. For example, identifying phenomena in the descriptive phase of investigation requires an analysis of data patterns and a rationale for deciding that a given pattern represents an aspect of the world such as a psychopathology symptom. The categorizing of symptoms into groups involves deeper theoretical analysis and complex judgements concerning their boundaries and relationships to underlying psychological mechanism and/or other symptoms. Finally, the strategy of epistemic iteration in the context of classification demands that researchers be clear about the meaning of initial categories and to justify any subsequent refinement and splitting or collapsing into higher level ones. Such clarity entails an awareness of the meaning (a conceptual task) of the relevant concepts in addition to the collection of statistical data.

\section{Seeking the "one true theory" and rejecting epistemic pluralism}

The allocation of offenders into risk bands (low, moderate or high) fails to inform practitioners which factors should be targeted in treatment, and how those factors can be addressed. That is, although risk-prediction instruments can tell us who possesses the greatest risk of re-offending, they fail to provide any therapeutically useful information about those individuals. In addition, the subscales of risk assessment instruments such as the Level of Services Inventory-R (e.g., attitudes/orientations, companions, accommodation-Bonta and Andrews 2017) measure state and surface features, which do not provide sufficient knowledge of the properties of problem behaviors. This leads to intervention plans that are inherently vague and nonspecific. In addition, because current classification systems grounded on offence type, risk level, and DRF were designed primarily for prediction purposes they do not offer much to policy makes and practitioners interested in resource allocation, treatment, and prison management. From this perspective the one "true theory" of classification is one oriented around risk prediction and management. It is simply assumed that a classification intended to ground risk prediction is suitable for treatment and other purposes. This is unlikely to be the case.

From what I said above it should be clear that given the competing interests of policy makers, police, researchers and practitioners, more than one classification system is likely to be required in forensic psychology. There is more than one way to "carve nature at its joints" in the criminal justice domain, depending on the questions you are asking: What is the likelihood someone will reoffend? What goals does an individuals' offending serve? What tasks are they engaged in? How should scarce criminal justice resources be allocated? How can we best promote desistance from offending? Each of these questions demands its own classification system; a relevant way of clustering characteristics 
of individuals and their relationships to the environments that is capable of meeting its specific aims. In other words, it makes more sense to develop a plurality of classification systems rather than seek to find the one "true system" that will meet the goals of all criminal justice personal and stakeholders.

If you accept the above argument, it is obvious that pluralism is the best strategy for developing classification systems tailored to the interests of different criminal justice actors. A one size fits all approach will not work. A comprehensive theory of method is likely to assist in the process because of its appreciation that research problems drive scientific investigation, and reflect quite distinct questions. There is no such thing as the best research problem; they vary depending on the practical and theoretical problems confronting individuals and institutions. Finally, the strategy of epistemic iteration with its commitment to falliblism, category refinement, and innovation logically entails a commitment to the development of multiple classification systems if the interests and task requirements of an inquiry process require it.

\section{Embracing impoverished theories of method and failure to distinguish distinct research tasks}

I will only make a few brief comments on the final two examples of theoretical illiteracy as what I have argued earlier is applicable in both instances. In short, reliance on restricted theories of method is likely to result in poor classification systems, primarily because of their neglect of conceptual and theoretical work. Given that I have argued that the construction of classification schemes is in part a theoretical task, it follows that any theory of method that ignores or minimizes the role of theory will lead to the other kind of illiteracy problems documented above. Furthermore, the endorsement of an impoverished theory of method means that the full range of distinct cognitive tasks associated with classification (and science) will be overlooked and there will be a significant risk of mistakenly thinking that one classification system can be equally valuable in the contexts of prediction, explanation, treatment planning and resource allocation. Adopting the three strategies of model pluralism, epistemic iteration, and following a comprehensive approach to inquiry, should minimizes the chances of this occurring. For example, understanding that description precedes explanation in science, and that there is more than one reasonable way to describe or group phenomena together, should encourage researchers to be explicit about what task they are engaged in and what problems they want a particular classification system to address (e.g., treatment planning versus risk prediction). Thus it is less likely that cognitive tasks of prediction, treatment planning, and explanation will be conflated. In turn, this should create a more dynamic and pluralistic scientific culture where competing ideas and different solutions to problems are actively encouraged.

\section{Conclusions}

In applied fields of science such as medicine and psychology sometimes the treatment of problems outstrips our understanding of their causes. We may know what works but not why it does. However, to make significant progress in the prevention and treating of the problems associated with crime it is necessary to identify their causes, and for this, we need theory. Theoretical illiteracy threatens the development and evaluation of good theories, and as such, is a significant obstacle to effective forensic psychological practice. Overcoming obstacles to theoretical literacy such as dogmatic thinking and the utilization of weak scientific methods requires that researchers and practitioners acknowledge the role of good theoretical work in science. Adopting knowledge increasing strategies such as epistemic iteration, explanatory pluralism, and using more comprehensive theories of method can assist in this process. In correctional settings, where decisions have real consequences, it is tempting to think there is one "best" way of doing things. But this type of thinking gets us further, not closer, to our objectives as forensic psychologists. To be ethical and competent practitioners we need to be theoretically literate as well as technically competent.

Conflict of interest T. Ward declares that he has no competing interests.

Open Access This article is licensed under a Creative Commons Attribution 4.0 International License, which permits use, sharing, adaptation, distribution and reproduction in any medium or format, as long as you give appropriate credit to the original author(s) and the source, provide a link to the Creative Commons licence, and indicate if changes were made. The images or other third party material in this article are included in the article's Creative Commons licence, unless indicated otherwise in a credit line to the material. If material is not included in the article's Creative Commons licence and your intended use is not permitted by statutory regulation or exceeds the permitted use, you will need to obtain permission directly from the copyright holder. To view a copy of this licence, visit http://creativecommons.org/licenses/by/4. $0 /$.

\section{References}

Andrews DA, Bonta J (2010) The psychology of criminal conduct, 5th edn. Anderson Publishing, New Providence

Anjum RL, Mumford S (2018) Causation in science and the methods of scientific discovery. Oxford University Press, New York

Barnett GD, Mann RE (2013) Cognition, empathy and sexual offending. Trauma Violence Abuse 14:22-33. https://doi.org/10.1177/ 1524838012467857

Beech AR, Ward T (2017) Theories of sex offending. Wiley-Blackwell, Oxford 
Beech AR, Wakeling HC, Szumski F, Freemantle N (2016) Problems in the measurement of dynamic risk factors in sexual offenders. Psychol Crime Law 22(1-2):68-83. https://doi.org/10.1080/ 1068316x.2015.1109095

Beggs S (2010) Within-treatment outcome among sexual offenders: a review. Aggress Violent Behav 15(5):369-379. https://doi.org/10. 1016/j.avb.2010.06.005

Bonta J, Andrews DA (2017) The psychology of criminal conduct, 6th edn. Routledge, New York

Borsboom D (2017) A network theory of mental disorders. World Psychiatry 16(1):5-13. https://doi.org/10.1002/wps.20375

Carter KC (2003) The raise of causal concepts of disease: case histories. Ashgate, Farnham

Chang H (2004) Inventing temperature and scientific progress. Oxford University Press, New York

Chang $\mathrm{H}$ (2012) Is water $\mathrm{H}_{2} \mathrm{O}$ : Evidence, realism, and pluralism. Springer, New York

Chang H (2017) Epistemic iteration and natural kinds: realism and pluralism in taxonomy. In: Kendler KS, Parnas J (eds) Philosophical issues in psychiatry: classification of psychiatric illness. Oxford University Press, New York, pp 229-245

Cording JR, Beggs Christofferson SM, Grace RC (2016) Challenges for the theory and application of dynamic risk factors. Psychol Crime Law 22:84-103. https://doi.org/10.1080/1068316x.2015. 1111367

Craver CF (2007) Explaining the brain: mechanisms and the mosaic unity of neuroscience. Oxford University Press, New York

Gaukroger S (2016) The natural and the human: science and the shaping of modernity. Oxford University Press, New York, pp 1739-1841

Haig BD (2014) Investigating the psychological world: scientific method in the behavioural sciences. MIT Press, Cambridge

Hanson RK (2009) The psychological assessment of risk for crime and violence. Can Psychol 50(3):172-182. https://doi.org/10.1037/ a0015726

Heffernan R, Ward T (2017) A comprehensive theory of dynamic risk and protective factors. Aggress Violent Behav 37:129-141. https://doi.org/10.1016/j.avb.2017.10.003

Heffernan R, Ward T (2019) Dynamic Risk Factors, Protective Factors, and Value-Laden Practices. Psychiat Psychol Law 26:312-28

Heffernan R, Wegerhoff D, Ward T (2019) Dynamic risk factors: conceptualization, measurement, and evidence. Aggress Violent Behav 48:6-16. https://doi.org/10.1016/j.avb.2019.06.004

Hochstein E (2016) Giving up on convergence and autonomy: why the theories of psychology and neuroscience are codependent as well as irreconcilable. Stud Hist Philos Sci Part A 56:135-144. https:// doi.org/10.1016/j.shpsa.2015.10.001

Klepfisz G, Daffern M, Day A (2016) Understanding dynamic risk factors for violence. Psychol Crime Law 22(1-2):124-137. https:// doi.org/10.1080/1068316X.2015.1109091

Kuhn TS (1970) The structure of scientific revolutions. University of Chicago Press, Chicago

Maibom HL (2012) The many faces of empathy and their relation to prosocial action and aggression inhibition. Wires Cog Sci 3:253-263. https://doi.org/10.1002/wcs.1165

Mann RE, Hanson RK, Thornton D (2010) Assessing risk for sexual recidivism: some proposals on the nature of psychologically meaningful risk factors. Sex Abuse 22(2):191-217. https://doi.org/10. 1177/1079063210366039

Marshall WL, Marshall LE, Serran GA, Fernandez YM (2006) Treating sexual offenders: An integrated approach. Routledge, New York
Nola R, Sankey H (2007) Theories of scientific method. Acumen, Stocksfield

Quinlivan R, Buckley J, James M, Twist A, Ball S, Duno M, Vissing J et al (2010) McArdle disease: a clinical review. J Neurol Neurosurg Psychiatry 81:1182-1188

Raine A, Dodge K, Loeber R, Gatzke-Kopp L, Lynam D, Reynolds C et al (2006) The reactive-proactive aggression questionnaire: differential correlates of reactive and proactive aggression in adolescent boys. Aggr Behav 32:159-171. https://doi.org/10.1002/ab.20115

Slaney K (2017) Validating psychological constructs: Historical, philosophical, and practical dimensions. Palgrave macmillan, London

Schindler S (2018) Theoretical virtues in science: uncovering reality through theory. Cambridge University Press, Cambridge

Schmucker, Losel F (2015) The effects of sexual offender treatment on recidivism: an international meta-analysis of sound quality evaluations. J Exp Criminol 11(4):597-630

Taxman FS, Caudy MS (2015) Risk tells us who, but not what or how: empirical assessment of the complexity of criminogenic needs to inform correctional programming. Criminol Public Policy 14:71-103. https://doi.org/10.1111/1745-9133.12116

Thornton D (2013) Implications of our developing understanding of risk and protective factors in the treatment of adult male sexual offenders. Int J Behav Consult Ther 8:62-65. https://doi.org/10. 1037/h0100985

Thornton D (2016) Developing a theory of dynamic risk. Psychol Crime Law 22:138-150. https://doi.org/10.1080/1068316x.2015. 1109092

Vreese LD, Weber E, Bouwel JV (2010) Explanatory pluralism in the medical sciences: theory and practice. Theor Med Bioeth 31:371-390. https://doi.org/10.1007/s11017-010-9156-7

Ward T (2014) The explanation of sexual offending: from single factor theories to integrative pluralism. J Sex Aggress 20:130-141

Ward T (2016) Dynamic risk factors: scientific kinds or predictive constructs. Psychol Crime Law 22(1-2):2-16. https://doi.org/10. 1080/1068316X.2015.1109094

Ward T, Carter E (2019) The classification of offending and crime related problems: a functional perspective. Psychol Crime Law 25:542-560. https://doi.org/10.1080/1068316X.2018.1557182

Ward T, Clack S (2019) From symptoms of psychopathology to the explanation of clinical phenomena. New Ideas Psychol 54:40-49. https://doi.org/10.1016/j.newideapsych.2019.01.004

Ward T, Fortune C (2016) The role of dynamic risk factors in the explanation of offending. Aggress Violent Behav 29:79-88. https:// doi.org/10.1016/j.avb.2016.06.007

Ward T, Hudson SM (1998) A model of the relapse process in sexual offenders. J Interpers Violence 13:700-725. https://doi.org/10. 1177/088626098013006003

Ward T, Durrant R, Sullivan J (2019) Understanding crime: a multilevel approach. Psychol Crime Law 25:709-711. https://doi.org/ 10.1080/1068316X.2019.1572754

Ward T, Melser J, Yates PM (2007) Reconstructing the risk need responsivity model: a theoretical elaboration and evaluation. Aggress Violent Behav 12:208-228. https://doi.org/10.1016/j. avb.2006.07.001

Ward T, Wilshire CE, Jackson L (2018) The contribution of neuroscience to forensic explanation. Psychol Crime Law 24:195-209. https://doi.org/10.1080/1068316X.2018.1427746

Wilkins JS, Ebach MC (2014) The nature of classification: relationships and kinds in the natural sciences. Palgrave MacMillian, Basingstoke 